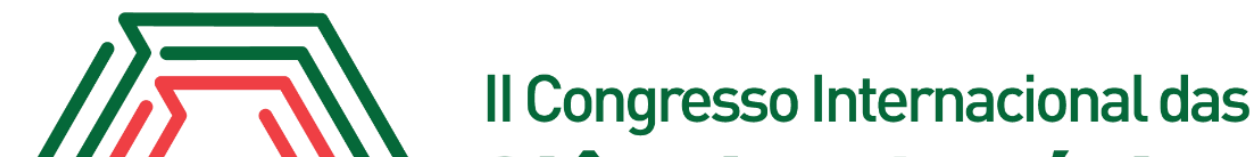 Ciências Agrárias COINTER - PDVAgro 2017
}

\section{CARACTERÍSTICAS ESTRUTURAIS DE SEIS CULTIVARES DE PANICUM NO PERÍODO DO ESTABELECIMENTO INICIAL}

\author{
Apresentação: Pôster
}

\begin{abstract}
Ana Beatriz Graciano da Costa ${ }^{1}$; Gelson dos Santos Difante ${ }^{2}$; João Virgínio Emerenciano Neto $^{3}$; Emmanuel Lievio de Lima Veras ${ }^{4}$; Jéssica Gomes Rodrigues ${ }^{5}$
\end{abstract}

\section{Introdução}

O sucesso na utilização de pastagens depende não só da disponibilidade de nutrientes ou da escolha da planta forrageira a ser utilizada, como também da compreensão dos mecanismos morfofisiológicos e de sua interação com o ambiente, ponto fundamental para suportar tanto o crescimento quanto a manutenção da capacidade produtiva da pastagem (GARCEZ NETO et al., 2002).

A morfogênese retrata a dinâmica de aparecimento e expansão dos componentes das plantas no tempo e no espaço (CHAPMAN; LEMAIRE, 1993). Através da morfogênese é possível chegar a cultivares adaptadas na região estudada, pois resultará as características estruturais dentre as quais a densidade populacional de perfilhos, fator este importante para se evitar a degradação de pastagens ou se determinar o período certo do estabelecimento de uma pastagem.

Este trabalho teve como por objetivo avaliar as características estruturais de seis cultivares de Panicum no período do estabelecimento.

\section{Fundamentação Teórica}

Para o sucesso no estabelecimento de pastagens devem ser levadas em conta as condições de solo e clima da propriedade, bem como o uso previsto para a pastagem e, em função desses fatores,

\footnotetext{
${ }^{1}$ Graduanda em Agronomia, bolsista PIBIC/CNPq - UFRN, Macaíba, RN. beatrizcosta.0303@hotmail.com

2 Professor do Programa de Pós-Graduação em Produção Animal - PPGPA - UFRN, Macaíba, RN. gdifante@ufrnet.br

${ }^{3}$ Professor do Colegiado de Zootecnia, UNIVASF, Petrolina, PE. joao_neto@zootecnista.com.br

${ }^{4}$ Mestre pelo Programa de Pós-Graduação em Produção Animal - UFRN, Macaíba, RN. emmanuel.veras@hotmail.com

${ }^{5}$ Bolsistas de Iniciação Científica CNPq e PROPESQ/ UFRN, Macaíba - RN. jessicagr1993@outlook.com
} 
escolher a espécie ou espécies adaptadas a essas condições.

Para produção animal em pastagem é necessário que haja uma associação perfeita entre planta e ambiente que, geralmente, é resultado de um bom estabelecimento e de um bom manejo do pasto. Dentre as características importantes para a determinação do estabelecimento de pastagens é a sua capacidade de produção de perfilhos. Segundo Gomide (2016), as gramíneas da espécie Panicum maximum estão entre as mais usadas no Brasil, principalmente para sistemas intensivos de produção de leite em pasto.

As gramíneas do gênero Panicum são conhecidas mundialmente por sua alta produtividade, qualidade e adaptação a diferentes condições edafoclimáticas. É uma espécie muito utilizada pelos pecuaristas por apresentar elevado acúmulo de biomassa entre as forrageiras tropicais propagadas por sementes, sua abundante produção de folhas longas, por sua aceitabilidade pelos animais e seu porte elevado (JANK et al., 2010).

O crescimento da vegetação depende da intercepção da radiação fotossinteticamente ativa (RFA) pelo dossel, da eficiência de uso da RFA interceptada e da partição de assimilados entre raiz e parte aérea. Desses processos, a intercepção da RFA é dependente, em grande parte, do IAF do dossel, o qual é condicionado pelo balanço entre os processos morfogênicos e pelo arranjo estrutural deles decorrente (DIFANTE, 2003). Isso comprova a descrição de morfogênese por Lemaire \& Chapman (1996) como a dinâmica de geração e expansão de órgãos vegetais no tempo e no espaço, sobre o rendimento de massa seca do dossel.

\section{Metodologia}

O experimento foi conduzido na área experimental do Grupo de Estudos em Forragicultura (GEFOR), situado na Unidade Acadêmica Especializada em Ciências Agrarias - Universidade Federal do Rio Grande do Norte - UFRN, em Macaíba, RN. No período de 09 de abril (dia da semeadura) a 29 de julho de 2016 (dia do corte).

$\mathrm{O}$ delineamento utilizado foi em blocos ao acaso com seis tratamentos e quatro repetições. Foram avaliadas seis gramíneas do gênero Panicum: Cultivares Tamani, Mombaça, Massai, Tanzânia, Aruana e Zuri. Cada bloco foi constituído de seis parcelas com o espaçamento de 1,0 m entre parcelas e 2,0 m entre blocos. O solo da área é classificado como Neossolo Quartzarênico (EMBRAPA, 2006).

As avaliações ocorreram semanalmente, para determinar a densidade populacional de perfilhos foram marcados dentro das parcelas dois quadrados de $0,250 \mathrm{~m}^{2}$ para a contagem de 
perfilhos nestes quadrados. O comprimento final da folha foi calculado pelo produto da taxa de expansão foliar e a duração do período de alongamento para uma dada folha (CFF, cm/perfilho). O número de folhas vivas por perfilho foi obtido sempre pelo máximo número de folhas durante o período de avaliação (NFV, folhas/perfilho). No dia do corte de uniformização, foram coletados quatro perfilhos aleatórios de cada parcela, para avaliar a altura do perfilho estendido, o número de folhas vivas em cada perfilho e o peso seco destes. Os perfilhos foram pesados em balança de precisão para estimativa do peso verde (PV), identificados com etiquetas de papel enumeradas, acondicionados em sacos de papel e levados a estufa de circulação forçada de ar a $55^{\circ} \mathrm{C}$ por 72 horas quando foram retirados e novamente pesados para estimativa do peso seco.

Os dados foram submetidos à análise de variância e as médias comparadas pelo teste de Tukey a 5\% de significância. Utilizou-se o seguinte modelo: Yijk $=\mu+\mathrm{Ci}+\mathrm{Bj}+\alpha i j$, em que: Yijk $=$ valor observado da cultivar i no bloco $\mathrm{j} ; \mu$ = efeito médio geral; $\mathrm{Ci}=$ efeito da cultivar $\mathrm{i}, \mathrm{i}=$ Tamani, Mombaça, Massai, Tanzânia, Aruana e Zuri; Bj= efeito do bloco j, j= 1-4; aij= erro aleatório associado as cada observação Yijk.

\section{Resultados e Discussões}

$\mathrm{O}$ comprimento final da folha (CFF) apresentou diferença significativa ( $\mathrm{P} 0,05)$ entre as cultivares, sendo a cultivar Mombaça com maiores valores. Esta cultivar apresentou diferença devido as suas características genéticas, Silveira (2006) encontrou valores semelhantes aos descritos neste trabalho.

Para a variável número de folhas vivas $(\mathrm{NFV})$ houve diferença $(\mathrm{P}<0,05)$ entre as cultivares, sendo a cultivar Aruana com maior valor (4,62 folhas/perfilho). Essa diferença ocorre porque enquanto as demais cultivares gastavam energia produzindo folhas maiores, a cultivar Aruana produzia mais folhas de tamanho menor.

Para densidade populacional de perfilhos (DPP) observou diferença significativa $(\mathrm{P}<0,05)$, sendo as cultivares Tamani, Mombaça e Tanzânia com maior produção de perfilhos durante o período de avaliação. As cultivares Massai, Aruana e Zuri resultaram os menores valores, isso pode ter ocorre por falta de algum fator abiótico, como por exemplo, água, ou devdido a um estabelecimento mais tardio comparado as demais cultivares. 
Ao comparar a densidade populacional de perfilhos (DPP) com o peso seco dos perfilhos, notou-se uma relação entre essas duas variáveis. Obteve-se apenas como exceção a cultivar Tamani, onde teve alta produção de perfilhos, porém perfilhos leves devido a sua pouca ou quase que nenhuma produção de colmo.

Tabela 1 - características estruturais de seis cultivares de Panicum: comprimento final da folha (CFF), número de folhas vivas (NFV), densidade populacional de perfilhos (DPP), peso seco (PS) e altura do perfilho estendido (APE).

\begin{tabular}{cccccccc}
\hline Variáveis & Tamani & Mombaça & Massai & Tanzânia & Aruana & Zuri & CV \\
\hline CFF & $102,86 \mathrm{ab}$ & $129,87 \mathrm{a}$ & $61,86 \mathrm{bc}$ & $92,20 \mathrm{ab}$ & $29,61 \mathrm{c}$ & $63,55 \mathrm{bc}$ & 47,87 \\
NFV & $3,56 \mathrm{ab}$ & $3,37 \mathrm{ab}$ & $3,25 \mathrm{~b}$ & $3,87 \mathrm{ab}$ & $4,62 \mathrm{a}$ & $2,87 \mathrm{~b}$ & 14,98 \\
DPP & $300,62 \mathrm{a}$ & $294,50 \mathrm{a}$ & $93,500 \mathrm{~b}$ & $238,12 \mathrm{a}$ & $152,00 \mathrm{ab}$ & $141,25 \mathrm{ab}$ & 28,89 \\
PS & $0,87 \mathrm{dc}$ & $2,60 \mathrm{a}$ & $0,45 \mathrm{~d}$ & $1,52 \mathrm{~b}$ & $1,01 \mathrm{bc}$ & $1,24 \mathrm{bc}$ & 26,29 \\
APE & $74,75 \mathrm{ab}$ & $84,19 \mathrm{a}$ & $51,62 \mathrm{c}$ & $73,37 \mathrm{ab}$ & $57,75 \mathrm{cb}$ & $63,37 \mathrm{abc}$ & 16,25 \\
\hline
\end{tabular}

Médias seguidas das mesmas letras, na linha não diferem $(\mathrm{P}>0,05)$ emtre si, segundo o teste Tukey.

$\mathrm{O}$ peso seco dos perfilhos diferiu $(\mathrm{P}<0,05)$ entre as cultivares, as cultivares Tamani e Massai tiveram menores valores. Isso pode ser explicado devido a menor quantidade e espessura de colmo dessas cultivares o que proporcionou uma menor massa.

A altura dos perfilhos estendidos variou entre as cultivares $(\mathrm{P}<0,05)$. Assim como observado na altura do dossel, a cultivar Mombaça teve a maior altura de perfilho. A cultivar Tamani obteve a segunda maior altura que não foi identificado na avaliação da altura do pasto, isso acontece devido ao acamamento das folhas dessa cultivar.

\section{Conclusões}

As cultivares de Panicum avaliadas tiveram estabelecimento adequado no período de avaliação, tendo destaque as cultivares Tamani, Mombaça e Tanzânia com melhores características estruturais. 


\section{Referências}

CHAPMAN, D.F.; LEMIRE, G. Morphogenetic and structural determinants of plant regrowth after defoliation. In: International Grassland Congress, 17, 1993, Proceedings..., p.95-104, 1993.

DIFANTE, Gelson dos Santos. IMPORTÂNCIA DA MORFOGÊNESE NO MANEJO DE GRAMÍNEAS FORRAGEIRAS. Viçosa: Ufv, 2003.

EMBRAPA. Centro Nacional de Pesquisa de Solos (Rio de Janeiro, RJ). Sistema brasileiro de classificação de solos. 2. ed. - Rio de Janeiro : EMBRAPA-SPI, 2006.

GARCEZ NETO, Américo Fróes et al. Respostas Morfogênicas e Estruturais de Panicum maximum cv. Mombaça sob Diferentes Níveis de Adubação Nitrogenada e Alturas de Corte. R. Bras. Zootec., Viçosa, v. 31, n. 5, p.1890-1900, ago. 2002.

GOMIDE, Carlos Augusto de Miranda et al. Panicum maximum cvs. Tanzânia e Mombaça para uso em pastejo: produção e custo. Juiz de Fora: Embrapa, 2016.

SILVEIRA, Márcia Cristina Teixeira da. Caracterização morfogênica de oito cultivares do gênero Brachiaria e dois do gênero Panicum. 2006. 111 f. Dissertação (Mestrado) - Curso de Zootecnia, Universidade Federal de Viçosa, Viçosa, 2006.

JANK, L. et al. Panicum maximum. In: FONSECA, D.M.; MARTUSCELLO, J.A. (Edt.). Plantas Forrageiras. Viçosa, MG. 2010. cap. 5.

LEMAIRE, G. CHAPMAN, D. Tissue flows in grazed plant communities. In: HODGSON, J., ILLIUS, A.W. The ecology and management of grazing systems. Wallingford: CAB International, 1996. p3-36. 